\title{
DOMINGO VILLAR: NOVELA NEGRA CON SABOR GALLEGO
}

\section{DOMINGO VILLAR: CRIME NOVEL WITH GALICIAN FLAVOUR} Javier SÁNCHEZ ZAPATERO

\author{
Universidad de Salamanca \\ zapa@usal.es
}

Resumen: El artículo analiza diversos aspectos temáticos y formales de las novelas policiacas de Domingo Villar protagonizadas por el inspector Leo Caldas.

Abstract: The paper analyzes some narratological and thematic aspects of the crime novels by Domingo Villar, featuring inspector Leo Caldas.

Palabras clave: Novela negra. Domingo Villar. Literatura gallega contemporánea. Literatura española contemporánea.

Key words: Crime Novel. Domingo Villar. Contemporary Galician Literature. Contemporary Spanish Literature. 


\section{EL AUTOR Y LA OBRA}

Nacido en Vigo en 1971, Domingo Villar «ha conseguido que su nombre se sitúe entre los más importantes de la novela policiaca española» (Rivero Grandoso, 2011: 179), gracias a la serie narrativa protagonizada por el inspector Leo Caldas, compuesta por Ojos de agua (2006), La playa de los ahogados (2009) y por el relato «El último verano de Paula Ris» $(2010)^{1}$. Su obra no solo ha merecido los halagos de la crítica especializada - Ayala Dip (2009) la ha calificado de «excelente», mientras que Pilar Castro (2009) ha afirmado que logra hacer de la «novela negra un ejercicio de estilo interesante y entretenido [...] que ofrece algo más una ocurrencia literaria afortunada»-, sino que ha sido galardonada con diversos premios literarios. Ojos de agua recibió el Premio Frei Martín Sarmiento y fue finalista en dos categorías de los Crime Thriller Awards —entregados en el Reino Unido y considerados los premios de ficción policiaca, tanto literaria como audiovisual, más prestigiosos de Europa-, mientras que La playa de los ahogados fue galardonada por las federaciones de libreros de Galicia y Madrid, y por asociaciones de lectores de novela policiaca como Novelpol o Brigada 21. Además, la serie protagonizada por el inspector Leo Caldas ha tenido una buena acogida entre el público, evidenciada en las más de treinta reediciones de su edición española, en el hecho de haber sido traducidas a decenas de lenguas o en poder contar por cientos de miles su número de lectores.

Grosso modo, las dos novelas de Villar se ajustan a la definición de género policiaco de José F. Colmeiro (1994: 55), por cuanto son narraciones «cuyo hilo conductor es la investigación de un hecho criminal», o a la de Rodríguez Pequeño (2008: 158), puesto que se basan en «una acción y un proceso: un crimen y la investigación de dicho crimen». Ojos de agua relata las pesquisas que el inspector de policía Leo Caldas realiza, con la colaboración del agente Rafael Estévez, para resolver el enigma que se esconde tras el cruel y sañudo asesinato de un músico de jazz; mientras que La playa de los ahogados tiene como punto de partida la aparición del cadáver de un marinero que es arrastrado por la marea hasta la orilla de una playa, pero que, al tener las manos atadas, no parece ni haberse suicidado ni haber sufrido un accidente. «El último verano de Paula Ris», por su parte, y a pesar

1 Villar es también autor de los relatos «Las hojas secas» (2009), incluido en la antología La lista negra. Nuevos culpables del policial español, y «Die Bestie von Oelde» (2010), editado originalmente en alemán en la compilación Mord am Hellweg IV. Además, ha publicado diversos cuentos en medios de comunicación. 
de relatar la búsqueda del asesino de una adolescente, sirve fundamentalmente para recrear la juventud del personaje de Leo Caldas. En su condición de «precuela», el cuento muestra al protagonista varias décadas antes del tiempo presente en el que transcurren sus novelas y narra un acontecimiento que permite explicar su decisión de convertirse en policía.

A diferencia de otras obras policiacas, en las que la presencia de la víctima y el culpable parece estar solo al servicio de la trama investigadora, en las novelas de Villar ambos personajes adquieren gran relevancia. Las novelas inciden en la «humanidad» de ambos. Así, a medida que las pesquisas de Caldas y su equipo se van desarrollando, el lector va entrando en contacto con la víctima, conociéndola gracias a las declaraciones de quienes la conocían, a la reconstrucción de sus rutinas y a la descripción de sus espacios íntimos, y con el culpable, descubriendo que el asesinato no tiene por qué estar siempre relacionado con los submundos del hampa o con las estructuras de crimen organizado, sino que cualquiera, por pacífico y convencional que parezca, puede ser responsable de una muerte violenta.

La importancia del contexto social y cultural de Galicia - y en concreto de Vigo y sus alrededores, zona en la que desarrolla su trabajo Caldas-, así como el hecho de que las novelas trasciendan con mucho el simple desafío intelectual del misterio y adquieran un valor de crónica de la contemporaneidad, provoca que la obra de Villar presente evidentes concomitancias con la narrativa negra. Aunque en numerosas ocasiones «novela negra» se utiliza como sinónimo de «novela policiaca», resulta más apropiado referirse a la primera como resultado de la reconversión de la segunda «en una literatura de alcance social que desdeña el universo burgués y el simple divertimento mental y, protagonizada por un nuevo tipo de detective [...], aborda con honestidad, rigor, y realismo la cotidiana realidad criminal» (Alonso y Santamaría, 1991: 22-23). Debido a la fertilidad que durante las últimas décadas ha tenido esta variante narrativa, así como a su camaleónica capacidad de evolución, que ha dado lugar a todo tipo de corrientes y movimientos, en las páginas siguientes enmarcaremos la «serie Caldas» dentro de dos tendencias del género negro perfectamente identificables: la novela costumbrista —basada en «el énfasis en la caracterización e introspección psicológica de los personajes y la importancia de la descripción de los usos y costumbres, paisajes y ambientes sociales» (Colmeiro, 1994: 63) — y la novela procedimental - distinguida por el detallismo y la verosimilitud con que muestra las rutinas de trabajo de los cuerpos policiales-. 
Además de por su adscripción genérica y por la reiteración de una serie de personajes y ambientes, las novelas de Domingo Villar aparecen vinculadas por la repetición de una serie de elementos formales, entre los que se han de destacar el uso de un narrador heterodiegético omnisciente; la sobriedad en el estilo de la escritura, basado en la frase corta y en la ausencia de elementos vacuos; la constante utilización del diálogo; la presencia del humor; y la brevedad de los capítulos, así como el hecho de que cada uno de sus títulos sea la entrada en el diccionario de una palabra polisémica que de algún u otro modo está relacionada con el contenido de la narración.

\section{EL CONTEXTO: ENTRE GALICIA Y ESPAÑA}

\subsection{Escritura y autotraducción}

Lo primero que llama la atención al aproximarse a la serie narrativa protagonizada por el inspector Leo Caldas es la condición de autotraductor de su autor. Al igual que otros escritores que proceden de zonas geográficas en las que conviven dos lenguas, Domingo Villar se ha encargado de las traducciones al español de sus obras, compuestas originalmente en gallego. Semejante actividad parece posible, además de por la lógica competencia idiomática, por la «biculturalidad» (Tanqueiro, 1999: 23), que permite al autor estar plenamente inmerso en dos contextos culturales diferentes, aunque repletos de conexiones, como el gallego y el español, y poseer «dos concepciones del mundo, $[\ldots]$ dos formas de verlo y entenderlo que se complementan y enriquecen» (Conde, 2002: 25). De hecho, son muchos los autores gallegos que han optado por la misma fórmula que Villar, encargándose ellos mismos en alguna ocasión de verter sus palabras al español, desde referentes clásicos como Rosalía de Castro, Alvaro Cunqueiro o Eduardo Blanco Amor hasta escritores contemporáneos como Manuel Rivas, Suso de Toro o Ramón Loureiro, hasta el punto de que es posible afirmar que «la autotraducción es un fenómeno que se encuentra presente de forma más que tangencial en las letras gallegas» (Dasilva, 2009: 143).

A pesar de que los estudios de Traductología acostumbran a situar a los autotraductores más cerca de los traductores que de los autores, y, en consecuencia, a la autotraducción como una variante — «sui géneris», según Tanqueiro (1999: 24); «privilegiada», según Dasilva (2013: 9)— de la traducción, casos como el de Villar evidencian que, en algunas ocasiones, la labor del autor que traslada sus propias palabras a otra lengua tiene más de crea- 
ción que de traslación. No en vano «el traducir su propia obra permite que el autor reflexione sobre el texto original, es una segunda oportunidad para mejorar y perfeccionar la versión original» (Gara Chefiri, 2010: 39). Así lo ha corroborado el propio Villar al explicar su peculiar forma de escritura, basada en la traducción casi simultánea y en la consiguiente imposibilidad de considerar que una versión procede de otra, puesto que ambas se van configurando prácticamente al mismo tiempo:

Escribo inicialmente en gallego y voy traduciendo al castellano en el mismo día. Acabo a la vez en los dos idiomas porque utilizo la traducción como corrección. [...] El idioma es la paleta del escritor y la fortuna es poder utilizar dos, contrastarlas, apoyarme en una y otra y mal haría si no lo hiciera. Pero traducir no es cambiar palabra por palabra. Es descomponer el texto, bajar al sustrato y volver a montarlo, lo que permite ver toda la arquitectura interna, los entresijos, con mayor perspectiva (Villar apud Mínguez, 2010).

Semejante proceso compositivo explica que las fechas de publicación de sus novelas en gallego y castellano coincidan -2006 (Ollos de auga/Ojos de agua) y 2009 (A praia dos afogados/La playa de los ahogados)—y que, en general, sus obras sean presentadas como si fueran escritas originariamente en cada una de las lenguas, como si no se hubiese efectuado una traducción. Así lo demuestran, por ejemplo, que la segunda novela del autor recibiera el ya mencionado Premio Brigada 21 a la mejor novela negra escrita en castellano o que su cuento «Las hojas secas» fuese incluido en la antología La lista negra. Nuevos culpables del policial español, con la que se intentaba trazar «un panorama de la narrativa negro-criminal española» (Martín Escribá y Sánchez Zapatero, 2009: 11) del siglo XXI. La consideración de Villar y del resto de autotraductores gallegos como representantes de la literatura española ha sido cuestionada por voces como la de Dasilva (2009: 146), quien ha criticado «la voracidad endocéntrica del Estado [...], que tiende a adueñarse de las obras de las literaturas periféricas que aparecen autotraducidas al castellano, propiciando que la identidad lingüística de muchos escritores acabe desvaneciéndose».

\subsection{Tradiciones literarias}

El hecho de que Domingo Villar acostumbre a ser identificado como representante de las literaturas gallega y española provoca que, a la hora de ser contextualizada, su obra haya de ser incluida en dos tradiciones diferen- 
tes, en las que, además, el subgénero narrativo en que se inscriben sus novelas ha evolucionado de forma distinta.

Por un lado, el autor ha de ser considerado uno de los principales cultivadores contemporáneos de la novela negra gallega. El desarrollo del género en Galicia es anómalo por el retraso con el que se implantó, ya que, según Ventura (2012: 136), hubo que esperar hasta 1984 para que se publicara «la primera novela de género claramente 'negrocriminal' escrita en lengua gallega, [con la que] [...] nacía también el primer detective literario en usar esta lengua: Nivardo Castro»: Crime en Compostela, de Carlos G. Reigosa, ganadora del premio Xerais de novela. La novela - profusamente reeditada en Galicia desde la década de 1980, pero no publicada en castellano hasta el año 2000 - relata la investigación llevada a cabo para desentrañar el asesinato de un rico empresario de la construcción en Santiago de Compostela, escenario físico, social y humano de los acontecimientos narrados. Tras Crime en Compostela, Nivardo Castro - que aparece siempre acompañado por el personaje de Carlos Conde - ha protagonizado otras tres novelas - $O$ misterio de barco perdido (1988), A guerra do tabaco (1996) y Narcos (2001) — en las que se han abordado algunas de las problemáticas sociales de mayor importancia en la Galicia contemporánea, como el narcotráfico.

Además del personaje de Reigosa - y de, evidentemente, el propio Caldas-, se han de destacar otros dos protagonistas seriales en la literatura policiaca gallega: Frank Soutelo y Horacio Dopico ${ }^{2}$. El primero, creado por Miguel Anxo Fernández y protagonista de Un nicho para Marilyn (2002), Luar no inferno (2006), Tres disparos e dous friames (2008) y Luna de cobiza (2011), es presentado como un estadounidense de orígenes gallegos - su padre era un exiliado republicano- que desarrolla su actividad en Malibú ${ }^{3}$ y en cuya composición aparecen numerosas referencias a personajes prototípicos de la novela negra clásica americana como Philip Marlowe. Mientras, el segundo, obra de Diego Ameixeiras, aparece en Baixo mínimos (2004), O cidadán do mes (2006) y, tangencialmente, en Asesinato no Consello Nacional (2010).

Ahora bien, para entender el desarrollo diacrónico del género en Galicia en las últimas décadas ha de hacerse referencia también a Suso de Toro. A

2 Otros personajes seriales de la literatura policiaca gallega son el inspector Gumersindo Nespereira, de Bieto Iglesias - traductor al gallego de la obra de Arthur Conan Doyle — o Toni Barreiro, de Manuel Forcedela.

${ }^{3}$ La última de sus entregas está ambientada en Galicia, lugar al que el protagonista se desplaza para pasar sus vacaciones. 
pesar de que no están estructuradas a partir de una investigación y de que, en consecuencia, no aparezcan en ellas personajes investigadores, novelas como Ambulancia (1990) o Calzados Lola (1997) han de encuadrarse dentro de la narrativa negra por la importancia que en ellas adquieren la violencia, el delito y el submundo criminal. Del mismo modo que autores clásicos como James M. Cain, o que referentes más cercanos como Andreu Martín, Suso de Toro indaga en las circunstancias personales y sociales que conducen a alguien a delinquir, por lo que en sus obras lo importante nunca reside en el «¿quién?», sino en el «ipor qué?». Semejante reflexión de la violencia contemporánea se enmarca en la Galicia contemporánea, un escenario que en sus novelas aparece continuamente escindido entre lo rural y lo urbano, lo arcaico y lo moderno, lo legendario y lo real...

Por otro lado, Domingo Villar ha sido considerado uno de los referentes de la novela policiaca española contemporánea, condición que compartiría con Lorenzo Silva, Alicia Giménez Bartlett, Eugenio Fuentes, Rafael Reig, José María Guelbenzu, Carlos Zanón o Willy Uribe ${ }^{4}$. Grosso modo, la producción de estos autores ha coincidido con el «rápido crecimiento [...] y el progresivo asentamiento de la novela policiaca en el panorama cultural» (Peñate, 2010: 7), producidos a partir de la década de 1990 debido a diversos factores: la asimilación de la herencia de la tradición literaria configurada por Manuel Vázquez Montalbán, Juan Madrid, Francisco González Ledesma o Andreu Martín en la época de la Transición; la adaptación de las estructuras sociales, políticas y económicas de la sociedad española a los condicionamientos exigidos por el género; el asentamiento de festivales y actividades de difusión como la Semana Negra de Gijón; el progresivo aumento del corpus académico e investigador dedicado al tema; el cada vez mayor interés tanto de las editoriales como de los lectores; la proliferación de traducciones de escritores de diversas nacionalidades y tendencias, etc.

A pesar de las evidentes diferencias temáticas y formales de la obra de estos autores, y de los riesgos que siempre conlleva proyectar una visión unitaria sobre una serie de escritores heterogéneos vinculados por su adscripción a unas características tradicionalmente identificadas como propias de un subgénero narrativo y por su coincidencia contextual, no parece muy descabellado señalar que una de las señas de identidad de la novela negra

4 Los cuatro primeros autores citados comenzaron sus series policiacas en la década de 1990, mientras que el resto, al igual que Villar, comenzó su andadura literaria en el siglo XXI —excepto Guelbenzu, con una destacada obra literaria a sus espaldas antes de publicar, en 2001, la primera de las novelas de la saga protagonizada por la jueza Mariana de Marco-. 
española durante la última década es su progresivo alejamiento de los modelos instaurados en la época de la Transición gracias a la obra de novelistas como los ya mencionados Vázquez Montalbán, Madrid, González Ledesma o Martín. Tal y como ha señalado Colmeiro (1994: 213), en la obra de estos autores es posible detectar un nexo común basado «en el reflejo de los problemas más acuciantes de la sociedad contemporánea» y, de forma más concreta, «en la crítica irónica e inconformista de la sociedad española contemporánea». De algún modo, es posible interpretar las novelas de quienes impulsaron el género negro en la literatura española durante los últimos años de la década de 1970 y los primeros de la de $1980^{5}$ como una crónica de los acontecimientos vividos durante los convulsos años de reforma política en España. En ese sentido, resulta sintomático que Juan Madrid (1986: 25) señalase que sus novelas se dedicaban a «viviseccionar el momento actual» o que Manuel Vázquez Montalbán (apud Tyras 2003: 103) definiese las diferentes entregas de la «serie Carvalho» como «novelas realistas, crónica de la que va a ser la vida española de transición desde la decadencia del franquismo». A pesar de que la dimensión social continúa estando presente - como evidencia el hecho de que el propio Villar (2010) haya definido su obra como un «retrato social»—, la narrativa negra contemporánea parece haber sustituido el cariz político - profundamente crítico y desencantadoque tuvo en la década de 1980 por un tono costumbrista. Semejante preocupación por los contextos físicos y culturales ha conllevado que, frente al protagonismo espacial de Barcelona y, en menor medida, de Madrid en las novelas 1970 y 1980, la novela policiaca española contemporánea haya desarrollado un proceso de «descentralización» que ha convertido en escenarios de la acción zonas geográficas de todo el país, como demuestra el caso de Galicia en la obra Domingo Villar ${ }^{6}$.

5 Debido a diversas circunstancias sociales, históricas, políticas y culturales —basadas, grosso modo, en la ausencia de una burguesía dominante que impulsase en el siglo XIX la creación de una tradición autóctona de literatura policiaca; en el desprecio con el que las elites culturales juzgaron siempre a las narrativas populares; y en la imposibilidad de que un tipo de novela basada en el desorden social y la criminalidad fructificase durante la dictadura franquista-, la novela negra no pudo desarrollarse en España hasta mediados de la década de 1970. Para profundizar en esta anómala evolución, pueden consultarse los estudios de Colmeiro (1994), Resina (1997), Sánchez Zapatero y Martín Escribà (2010), Valles Calatrava (1991) o Vázquez de Parga (1993).

6 Otros ejemplos de esta «deslocalización» son los casos de Eugenio Fuentes, que ambienta sus obras en un escenario ficticio llamado Breda que parece corresponderse con una ciudad de provincias ubicada en el norte de Extremadura; Willy Uribe, que acostumbra a hacer del País Vasco escenario de sus novelas; o Lorenzo Silva, cuyos personajes investigadores han de resolver casos por diversos lugares de España. 
Otra de las características distintivas de la novela policiaca de las últimas décadas es el abandono de las figuras protagónicas detectivescas, relegadas a una presencia casi testimonial, y la consiguiente utilización de funcionarios públicos vinculados a los Cuerpos de Seguridad del Estado. De semejante característica, también observable en la novela europea ${ }^{7}$, dan fe casos como los de Lorenzo Silva y el agente de la guardia civil Rubén Bevilacqua; Alicia Giménez Bartlett y la investigadora policial Petra Delicado; José María Guelbenzu y la juez de instrucción Mariana de Marco; y el propio Villar y su inspector Leo Caldas. La utilización de este tipo de personajes parece provocada tanto por el paulatino alejamiento de los cuerpos policiales de la negativa imagen que en muchos sectores sociales tenían por su brutalidad y capacidad represiva durante el franquismo como por el hecho de que, en la actualidad, la verosimilitud que exige toda obra de género era difícil de cumplir con personajes detectivescos ${ }^{8}$. Tal y como ya ha sido mencionado, el uso reiterativo de personajes policiales vincula la obra de los autores mencionados con la variante procedimental de la literatura policiaca, caracterizada por su afán en mostrar, con todo lujo de detalles, los procedimientos oficiales que se han de seguir para llevar a cabo una investigación y en reflejar la cotidianeidad del trabajo policial, tanto la que se refiere a la actividad burocrática — redacción de informes, relación con las autoridades judiciales encargadas de instruir los casos, etc.- como la de sus pesquisas — búsqueda de pistas, interrogatorios, seguimiento a sospechosos, colaboración con forenses y expertos en diversas materias, etc.-

\section{LA «SERIE LEO CALDAS»}

\subsection{El inspector y la investigación}

Inspector de policía en la comisaría de Vigo, Leo Caldas es el protagonista de las novelas de Domingo Villar. Su importancia no solo reside en su condición de responsable de las investigaciones que sustentan la trama, sino

7 Sin ánimo de exhaustividad, entre la nómina de personajes de la novela policiaca europea que son miembros de los Cuerpos de Seguridad puede citarse a Kurt Wallander — del sueco Henning Mankell_, Salvo Montalbano — del italiano Andrea Camilleri_, Jean Baptiste Adamsberg — de la francesa Fred Vargas - o Kostas Jaritos — del griego Petros Markáris—.

8 Teniendo en cuenta que en actualmente la ley prohíbe la intromisión del detective privado en casos criminales y que, además, las fuerzas policiales cuentan a su disposición con toda una serie de métodos científicos y tecnológicos que convierten en insuficientes los recursos con los que pueden contar otro tipo de investigadores, la utilización de representantes de las fuerzas de Seguridad del Estado resultaba lo más adecuado para el carácter realista, de crónica de la sociedad contemporánea, que Villar parece querer dar a sus obras. 
también en el hecho de que es el único personaje de cuya vida personal da cuenta el narrador heterodiégetico de las novelas. De ese modo, el lector conoce tanto su habilidad para resolver los casos y su forma de relacionarse con sus colegas profesionales como su carácter y algunos episodios de su vida personal. De hecho, aunque cada una de las entregas de la serie tiene un carácter clausurado que permite leerlas de forma independiente, la evolución de Caldas, así como la presencia recurrente de una serie de elementos - espacios, personajes, rutinas, etc. - dota al proyecto narrativo de una continuidad que aconseja a leer las novelas que lo conforman siguiendo el orden cronológico de publicación y, en consecuencia, interpretándolas como una continua indagación en la personalidad del protagonista. Así, el lector va conociendo de forma progresiva el carácter del personaje - taciturno, melancólico, tímido y solitario-, algunas de sus aficiones —entre las que destacan su gusto por el vino, la buena mesa y el tabaco - y fobias — no le gustan los medios de transporte, ya que se marea con facilidad-, etc. También se mencionan algunos episodios de su vida pasada, entre los que tienen especial relevancia el hecho de que su madre muriera cuando él era niño y, sobre todo, su relación sentimental con Alba, un personaje que, a pesar de aparecer solo en La playa de los ahogados a través de una conversación telefónica, está presente de forma latente en toda la serie. Aunque apenas hay menciones explícitas, por la forma en la que Caldas recuerda el tiempo pasado a su lado se intuye que continúa enamorado a ella. La importancia que adquiere el personaje se pone de manifiesto en La playa de los ahogados, que termina precisamente con un diálogo en el que el padre de Caldas le anima a llamarla y retomar el contacto con ella:

- Tú todavía no la has llamado, ¿verdad?

- No, aún no.

- ¿Y no crees que deberías hacerlo? (Villar, 2009: 445).

Además de Alba y de sus compañeros de trabajo, en las dos novelas aparece su contexto familiar y de amistades, formado básicamente por su padre - con quien le une una singular relación caracterizada por la contención con la que ambos se expresan, y por su gusto compartido por el vinoy por los camareros y el grupo de parroquianos con los que diariamente se encuentra en el bar «Eligio»:

Eligio no solo era una especie protegida por el aroma a piedra, madera y sabiduría. Su secreto mejor guardado no estaba a la vista, sino en la pequeña cocina apartada de los ojos del visitante, en la que se preparaba el 
pulpo más tierno de la ciudad. Leo Caldas había cenado en la barra, charlando con Carlos, mientras los catedráticos debatían en la mesa contigua (Villar, 2006: 83).

El «Eligio», que aparece recurrentemente en todas las novelas, cumple la función de «espacio estable» que, según Balló y Pérez (2005: 10), sirve para que el lector pueda sentir la gratificación de volverse a encontrar con lo ya conocido en otras entregas de la serie. En la literatura serial detectivesca, el «espacio estable» tiene además la función de convertirse en «un centro de operaciones en el que el detective pensador recopila los hechos, extrae conclusiones y explora salidas de futuro» (Balló y Pérez, 2005: 37). Así ocurre en el «Eligio», donde Caldas, además de beber y comer, acostumbra a charlar con Carlos, el camarero, y con un grupo de fieles clientes a quienes apodan «los catedráticos», sobre los casos en los que está trabajando. Esas conversaciones permiten al investigador reflexionar sobre aquello que ha de resolver, ordenar las pistas obtenidas hasta el momento e incluso, en ocasiones, tal y como ocurre en Ojos de agua, vislumbrar la solución al misterio (Villar, 2006: 166).

Además del bar —y de, claro está, la comisaría en la que trabaja—, el otro «espacio estable» que acostumbra a aparecer en las novelas es la emisora de radio local con la que Caldas colabora. El inspector interviene en un programa semanal llamado «Patrulla en las ondas». Su función es la de atender las quejas, sugerencias y peticiones que los oyentes hacen, relacionadas a menudo con cuestiones de seguridad y civismo cuya competencia no depende del cuerpo policial al que pertenece, sino a la policía local. La imposibilidad de ayudar a quienes intervienen hace que Caldas no esté especialmente orgulloso de su participación, a lo que también contribuyen su mala relación con el locutor principal y al hecho de que el éxito del espacio radiofónico lo haya convertido en una «celebridad local» conocida por casi todos en la ciudad de Vigo: «a pesar de los años de servicio ciudadano en el cuerpo de policía, si alguien le conocía era por aquel absurdo programa de radio» (Villar, 2009: 236).

Por lo que se refiere a su labor como policía, de la lectura de las novelas parece deducirse su intuición y capacidad para fijarse en los pequeños detalles para resolver los casos. Para Caldas, «la información recabada en las primeras horas era siempre la más útil para la investigación» (Villar, 2009: 187), por lo que «le gustaba adentrarse en los primeros momentos en la escena del crimen y escudriñarla tratando de localizar la esencia del criminal impregnada en el lugar» (Villa, 2009: 187). La importancia de los primeros 
contactos con el escenario del crimen, así como la habilidad del inspector para dar sentido a algo que en un primer momento pasó desapercibido y encontrar así la solución del caso, queda evidenciada en el siguiente pasaje de Ojos de agua:

Volvió a tener la impresión de que estaba pasando por alto algún detalle importante. No podía identificarlo, pero una pequeña lucecita brillaba en su interior susurrándole que alguna pieza no encajaba en algún puzzle. Conocía aquella sensación y se fiaba de su instinto. Estaba seguro de que, por pequeño que fuera, lo que ahora se escondía en algún rincón de su cabeza terminaría por mostrarse de un modo repentino más tarde o más temprano (Villar, 2006: 57).

Otra de las características que aparece reflejada en las obras es la dedicación al trabajo de Leo Caldas, que le lleva a volcarse en las investigaciones de tal forma que incluso su vida personal parece quedar relegada a un segundo plano, tal y como le reprocha en La playa de los ahogados su colaborador habitual, el agente Estévez:

- A usted le da lo mismo llamar de noche que de día; para usted no hay diferencia entre un martes, un viernes o un domingo. Todos los días son iguales. Descuelga el teléfono y suelta su rollo sin molestarse siquiera en preguntar si los demás están ocupados [...]. Yo no tengo la culpa de que su vida se reduzca al trabajo —dijo [Estevéz]—, pero tiene que comprender que no todo el mundo es como usted (Villar, 2009: 283).

La actividad policial aparece reflejada en las novelas de Villar como una labor grupal. Aunque Caldas dirige y toma las principales decisiones en las investigaciones, nunca afronta en solitario la resolución de los casos. Así, aparecen de forma reiterativa personajes como Clara Barcia - miembro de la policía científica que se encarga de análisis técnicos, relacionados con cuestiones químicas, balísticas, tecnológicas o de huellas dactilares-o Guzmán Barrio - forense-, cuyas aportaciones acostumbran a ser de vital importancia para sacar adelante los casos. La minuciosidad con la que se describe la actividad de ambos pone de manifiesto la vinculación de las novelas con la variante procedimental, caracterizada, como ya se ha apuntado, por el detallismo verista con el que se muestran las rutinas policiales. 


\subsection{El personaje de Estévez y la presencia del humor}

Sin embargo, el personaje que mayor importancia adquiere de todos los que trabajan con Caldas es su ayudante Rafael Estévez, quien le acompaña habitualmente a inspeccionar los escenarios de los crímenes y realizar los interrogatorios. Su presencia, como ha advertido Rivero Grandoso (2011: 112), ayuda «al cumplimiento de un requisito de verosimilitud, ya que la policía trabaja generalmente en parejas» $\mathrm{y}$ «como recurso narrativo para establecer el diálogo con Caldas, a la manera cervantina, o, citando a los clásicos policiales, como Sherlock Holmes y Watson, o Hercule Poirot y Arthur Hastings». Juntos forman una heterogénea, pero bien complementada, pareja en la que el laconismo y la timidez de Caldas contrastan con la rudeza y el carácter lenguaraz de Estévez, a quien «su temperamento violento y su cabezonería [...] le dificultan enormemente su trabajo» (Rivero Grandoso, 2011: 111). En las novelas, de hecho, se narran diversos episodios de agresiones protagonizadas por el agente, así como las quejas que sobre sus actuaciones vierten algunos de sus superiores en la comisaría.

A Estévez, de origen aragonés, le cuesta adaptarse al nuevo contexto al que ha sido trasladado para desarrollar su actividad profesional, tal y como indica el narrador en Ojos de agua:

Rafael Estévez había recalado en Galicia pocos meses atrás. Su traslado se debía, según se rumoreaba en comisaría, a un castigo que alguien le había impuesto en su Zaragoza natal. El agente había aceptado sin especial desagrado trabajar en Vigo, aunque había algunas cosas a las que le estaba costando más tiempo del previsto acostumbrarse. Una era lo impredecible del clima, en variación constante, otra la continua pendiente de las calles de la ciudad, la tercera era la ambigüedad. En la recia mente aragonesa de Rafael Estévez las cosas eran o no eran, se hacían o se dejaban de hacer, y le suponía un considerable esfuerzo desentrañar las expresiones cargadas de vaguedades de sus nuevos conciudadanos (Villar, 2009: 16).

El extrañamiento que para el agente supone el nuevo espacio en el que ha de vivir y trabajar cumple dos funciones en la narración. Por un lado, su desconocimiento de diversos aspectos de la cultura, las costumbres o el paisaje gallegos — con los que tiene su primer contacto gracias a su traslado profesional- se convierten en eje de muchos de sus diálogos con Caldas, que tiene que explicar a su compañero, entre otras cosas, el modo de preparar percebes (Villar, 2009: 305) o las supersticiones marineras (Villar, 2009: 97). Asimismo, el descubrimiento que para Estévez supone Galicia le lleva 
a admirar los paisajes de la costa — «acostumbrado al invariable Mediterráneo, le sorprendía la cantidad de playa que había descubierto al reflujo de la marea» (Villar, 2006: 81)—, la belleza de los cementerios — «no sé si es la piedra cubierta de musgo, las cruces o qué, pero desde luego en mi tierra no son así» (Villar, 2006: 75) — o las excelencias de una gastronomía que le permite probar productos hasta entonces desconocidos para él — «gracias por los percebes, son un descubrimiento» (Villar, 2009: 320). De ahí que Díaz Sánchez (2012: 31) haya calificado al personaje como «descodificador» que permite descubrir «a través de los ojos del foráneo que no entiende ni trata de hacerlo» los elementos costumbristas gallegos.

Por otro lado, la incapacidad de Estévez para adaptarse al nuevo medio aparece también al servicio del humor, característica definitoria de las obras de Domingo Villar, que, según Rivero Grandoso (2011: 114), «sirve de contrapunto a la seriedad y el dramatismo propio de los crímenes que se relatan». La incomprensión del entorno - que le lleva a comer los percebes con piel (Villar, 2009: 320), a quejarse por la constante lluvia (Villar, 2009: 68) o a bañarse en la playa sin reparar en la presencia de fanecas que le dejan malherido (Villar, 2006: 82) — está en la base de casi todas las escenas humorísticas que aparecen en Ojos de agua y La playa de los ahogados. Pero, sin lugar a dudas, es el contraste entre la forma de ser del agente aragonés y la de quienes le rodean el elemento que acostumbra a producir la hilaridad en el lector. Villar utiliza algunos de los más identificables estereotipos de la personalidad gallega - la ambigüedad, la indecisión, la tendencia a no dar preguntas concretas y de responder a una pregunta con otra, etc.- para contraponerlos a la forma de ser de Estévez — directo y franco-, tal y como se puede observar en el siguiente pasaje de La playa de los ahogados:

- ¿Qué me recomienda?

- Los choquitos están saliendo muy buenos —dijo Cristina. Y casi al instante añadió-: Y el bacalao tiene mucho éxito también.

Dejó colgando las palabras y Estévez la miró fijamente esperando su veredicto. Tras unos segundos, viendo que este no se producía, preguntó:

- ¿Entonces?

- Son distintos — se limitó a decir la camarera.

- Eso ya lo sé. Pero alguno estará mejor —insistió el aragonés.

- Los dos están muy ricos —contestó con una sonrisa franca-. ¿A usted qué le gusta más?

- Olvídelo - refunfuñó el policía al ver que no iba a obtener la respuesta que buscaba-. Tráigame lo mismo que a él: los chocos esos..., y un poco de ensalada. 
En cuanto Cristina se perdió en el vocerío del comedor, Rafael Estévez. protestó:

- No sé para qué coño pregunto nada a esa gente (Villar, 2009: 34-35).

\subsection{Galicia, marco físico y cultural}

Más allá de su valor al servicio del extrañamiento de Estévez, la presencia del espacio geográfico y cultural de Galicia está determinada por su condición de escenario de la acción de las dos novelas. No hay que olvidar, en ese sentido, que el propio Villar ha llegado a manifestar que «la investigación policial no es más que una excusa para contar lo que sucede alrededor» (Rivero Grandoso, 2011: 180) e incluso que su obra puede ser considerada «un canto de amor» (Villar apud Baena, 2010) a Galicia. La condición de emigrante del autor, afincado en Madrid desde hace años, permite explicar la importancia que el territorio en el que creció adquiere en sus novelas, como él mismo ha confesado:

Sufro la legendaria morriña [...] y la escritura es la manera que he encontrado de aliviarla, pues me permite estar casi a diario en casa a pesar de estar físicamente a más de 600 kilómetros de distancia. Delante del teclado y de la pantalla del ordenador, viajo hasta Galicia y busco los escenarios en los que pasé mi niñez y mi juventud (Villar, 2010: 63).

Como trabajadores de la comisaria de Vigo, Caldas y Estévez han de ocuparse de casos criminales que ocurren tanto en el entorno urbano como en las zonas rurales de los alrededores ${ }^{9}$. En Ojos de agua los personajes se desplazan fundamentalmente por la ciudad de Vigo, de la que se mencionan de forma explícita cuestiones relacionadas con su historia — «bordearon el antiguo puerto del Berbés, donde se había iniciado la actividad marinera de la ciudad a finales del siglo XIX» (Villar, 2006: 20)—y, sobre todo, se describen referentes especiales susceptibles de ser recorridos de forma análoga en la vida real por cualquier lector:

Caldas atravesó la calle del Príncipe, cruzó la Puerta del Sol y pasó un arco que en otros tiempos había sido una de las puertas de la ciudad vieja. Descendió por el empedrado dejando a la derecha la biblioteca universitaria y la casa episcopal. Tomó la calleja que llevaba a la concatedral, en dirección opuesta al templo, y bajó por la calle Gamboa (Villar, 2006: 83-84).

9 Manuel Forcadela, en Sangue sobre a neve (1990), y Cid Cabido, en Unha historia que non vou contar (2009), han sido otros de los autores que han hecho de Vigo escenario de novelas negras. 
Caldas no es un investigador estático. En las jornadas que permanece enfrascado en la resolución de un caso apenas pasa tiempo en la comisaría, sino que se desplaza continuamente para obtener nuevas pistas, interrogar a testigos y sospechosos, acudir a las instalaciones de la policía científica para saber de sus averiguaciones, etc., con lo que el retrato espacial y social que efectúan sus obras es global y variado, puesto que da cuenta de diversos ambientes y lugares. De este modo, se pone de manifiesto la importancia que el marco urbano adquiere en el género negro, tanto por el hecho de que «el progreso del detective [se] materializa en el recorrido de la ciudad y la apertura de sus recovecos» (Resina, 1997: 48) como por la posibilidad de dotar al espacio de un valor metonímico capaz de transmitir las sensaciones del personaje. Tal y como ha mostrado Díaz Sánchez (2012: 19), «la ciudad pontevedresa acompaña al inspector en las pesquisas [...] que se acercan y se alejan de la verdad de la misma manera que él sube y baja las empinadas calles viguesas [...] como un símbolo del esfuerzo que se ha de llevar a cabo para lograr encontrar nuevas pistas que ayuden a avanzar en su investigación».

Frente al carácter urbano de Ojos de agua, en La playa de los ahogados adquiere gran relevancia el espacio rural - especialmente importante en Galicia, donde un elevado porcentaje de la población está disperso en asentamientos alejados de las grandes ciudades-, puesto que Caldas y Estévez han de investigar el asesinato de un marinero cuyo cadáver aparece en la playa de Panxón, pequeña localidad de tradición pesquera situada al sur de Vigo. En la novela, en consecuencia, aparecen numerosas descripciones de espacios naturales típicos del espacio gallego — playas, acantilados, montes, bosques, etc.- - así como observaciones sobre cuestiones relacionadas con la historia o la etimología de algunos de los lugares de la zona: «a medida que se alejaba del pueblo quedaba desguarnecida, tan abierta al Atlántico que los viejos marineros aseguraban que América era el primer obstáculo en la ruta si se navegaba en línea recta hacia el oeste. Por eso, al cruzar el riachuelo el arenal dejaba de llamarse Panxón y pasaba a llamarse Playa América» (Villar, 2009: 71). Además, el hecho de situar el punto de partida del argumento en un pueblo costero permite reflejar en la novela tradiciones, supersticiones y costumbres vinculadas con la cultura marinera. Así, se explica el funcionamiento de la lonja (Villar, 2009: 76-77), el significado de los amuletos que suelen llevar consigo quienes trabajar en la mar (Villar, 2009: 97), la forma de pescar con nasas (Villar, 2009: 100), etc.

La presencia del espacio rural sirve al narrador para cuestionar la transformación que ha sufrido en las últimas décadas el paisaje gallego por culpa del «asedio urbanizador» (Villar, 2009: 232). A esa mirada crítica sobre la 
destrucción de diversos parajes naturales, especialmente costeros, contribuye la actitud del personaje de Caldas, que parece retener en su memoria una imagen de Galicia diferente a la actual, con menos edificaciones y muchas más zonas litorales vírgenes:

Pese a no haber vuelto desde niño, Leo Caldas recordaba nítidamente a los árboles plantados en la orilla de la playa de Lapamán. Recordaba la arena ligera, más blanca de lo habitual, y las dornas varadas en la playa. El aroma a pintura, mar y madera de aquellas barcas pequeñas había perdurado evocadoramente vivo en su memoria (Villar, 2006: 82).

En La playa de los ahogados, la reflexión sobre la evolución de la geografía gallega no solo se centra en los cambios que el paso del tiempo y las decisiones políticas han tenido sobre el paisaje natural, sino también en las modificaciones que los nuevos tiempos han tenido sobre el clima moral y el ambiente social. De ahí que en la novela pueda detectarse un halo de nostalgia hacia otras culturas y formas de vivir identificadas con el pasado, y manifestadas, por un lado, en la proliferación de personajes de avanzada edad - el padre y el tío de Caldas, el doctor Trabazo, el párroco o algunos de los marineros que frecuentan el puerto de Panxón-y, por otro, en la referencia a la película de David Lynch Una historia verdadera (The Straight Story, 1999), centrada en el viaje que hace un anciano en una máquina cortacésped para visitar a un hermano con el que lleva años enemistado.

Galicia no solo está presente en la novela a través de las descripciones geográficas, de las referencias a lugares concretos o del reflejo de algunos de los más difundidos estereotipos sobre la forma de ser sus habitantes. También aparecen en las dos novelas elementos relacionados con su cultura, entre los que la gastronomía tiene un papel preponderante. Su presencia parece deberse a dos moti$\operatorname{vos}^{10}$. En primer lugar, es un elemento al servicio del retrato del protagonista, puesto que, como ya se ha dicho, Caldas es un excelente gourmet. Al igual que otros personajes de la novela negra contemporánea como Pepe Carvalho, Mario

10 La comida está presente en las novelas de diversos modos, puesto que, además de relatarse la forma en la que el inspector disfruta de las excelencias de la gastronomía gallega, también aparecen recetas: «Pones a hervir agua de mar con una hoja de laurel... [...] Puede ser agua del grifo con sal — dijo el inspector- Cuando hierva a borbotones, echas los percebes y esperas hasta que el agua rompa a hervir otra vez. Entonces cuentas hasta cincuenta, escurres el agua, vuelcas los percebes en una fuente y a la mesa [...] Calientes. Tapados con un paño para que no se enfríen» (Villar, 2009: 300). 
Conde, Salvo Montalbano o Fabio Montale ${ }^{11}$, el protagonista de las novelas de Villar no solo aprecia la exquisitez culinaria, sino que también van a otorgar a la comida un valor totémico, hedonista y social. De hecho, Caldas, a pesar de ser un personaje profundamente retraído, nunca come solo, sino que siempre lo hace acompañado por Estévez, por su padre o por los parroquianos del «Eligio». Y en segundo lugar, la presencia de la comida ha de ser interpretada como parte de la intención de Villar de dotar de un «color local» gallego a sus obras, puesto que los alimentos y platos que aparecen son típicos de la gastronomía de la zona ${ }^{12}$, tal y como puede observarse en el siguiente pasaje de Ojos de agua:

Se limpió las manos para alcanzar la helada jarra de barro que contenía el vino blanco y volver a llenarse la copa. Encontraba aquel vino casero demasiado ácido, pero agradecía su frescor. Después sujetó el pescado con una mano por la cabeza y con la otra por la cola, se lo acercó a la boca y mordió con fruición la carne salada. Dejó el pez a medio comer en el plato y aplastó con el tenedor el cachelo sobre el que había reposado la sardina. Colocó la patata deshecha en una rebanada de pan de maíz y le dio un bocado. Luego volvió a la sardina y le hincó el diente a la otra mitad. Después de casi un año sin probarlas, le sabían a gloria (Villar, 2006: 73).

\subsection{Referencias literarias y conciencia de género}

En las novelas de Domingo Villar pueden encontrarse numerosas referencias de carácter literario ${ }^{13}$. En Ojos de agua, por ejemplo, Caldas reme-

${ }_{11}$ Respectivamente, personajes de Manuel Vázquez Montalbán, Jean-Claude Izzo, Andrea Camilleri y Leonardo Padura.

${ }_{12} \mathrm{Al}$ igual que ocurre con la obra de otros autores como Vázquez Montalbán o Camilleri, en las novelas de Villar el gusto por la comida autóctona ha de relacionarse, además de con el tono costumbrista subyacente, con la voluntaria defensa de los elementos de la cultura popular, que le lleva a reivindicar la cocina tradicional gallega como «vía de recuperación de las señas de identidad colectivas» (Colmeiro, 1994: 87).

13 Además de estas alusiones, en la primera entrega de la serie puede encontrarse una irónica referencia metaficcional en una de las conversaciones que Caldas mantiene con los parroquianos habituales del Eligio:

Desde la mesa vecina, el catedrático que hojeaba el diario preguntó a Caldas si había estado implicado en el caso Zuriaga.

- Algo tuve que ver - respondió parcamente.

- Deberían escribir una novela con tus andanzas, Leo - dijo otro de los profesores.

- Claro - aseguró el inspector con un guiño.

- Hablo en serio —insistió el catedrático-, las novelas policiacas funcionan muy bien (Villar, 2006: 165-166). 
mora un pasaje de La colmena (Villar, 2006: 70), mientras que el narrador, al relatar el origen del «Eligio», explica cómo «junto a los barriles de roble apilado en el suelo irregular, habían conversado Álvaro Cunqueiro, Castroviejo, Blanco Amor y otros hombres ilustres» (Villar, 2006: 39).

No obstante, consciente de su condición de escritor de género, Villar incluye numerosos guiños a autores de novela negra. De ahí que resulte sintomático que la víctima de la primera de sus obras se apellide precisamente Reigosa o que, al inspeccionar su casa, el inspector se sorprenda al «encontrar casi exclusivamente novelas de género policiaco en la librería del músico: Montalbán, Ellroy, Chandler, Hammett...» (Villar, 2006: 32) y al descubrir que la novela que el muerto había dejado sin terminar era «El perro de Terracota, de Andrea Camilleri» (Villar, 2006: 32).

Sin llegar a mencionarla directamente, en La playa de los ahogados hay una referencia implícita a Fred Vargas y a su novela Huye rápido, vete lejos: «Se acordó de una novela policiaca de una autora francesa que Alba le había regalado un par de años atrás. Hacía tiempo que había olvidado la trama, pero recordaba a Joss, uno de sus personajes» (Villar, 2009: 72). Lejos de ser baladí, la alusión queda plenamente justificada, puesto que el argumento de la novela recuerda al de muchos de la autora francesa. En la novela de Villar, la aparición de un cadáver es vinculada por muchos de los habitantes de Panxón con el fantasma de un capitán de barco, fallecido años atrás en el naufragio de un barco entre cuya tripulación se encontraba, precisamente, el marinero que aparece asesinado. La creencia en sucesos irracionales - típica, en cierto modo, del folclore gallego, donde la presencia de conjuros y meigas es habitual- hace que muchos pescadores de la zona se protejan con diversos rituales y amuletos: para espantar al fantasma, algunos salen a faenar llevando una pequeña bolsa con sal o una higa, mientras que otros, cuando son preguntados por el tema por Caldas y Estévez, escupen. La labor del policía, de este modo, será la de utilizar la razón para esclarecer los crímenes y acabar con la superchería. Análoga situación acostumbra a producirse en las novelas de Vargas, sobre todo en las de la serie narrativa protagonizada por el comisario Adamsberg, en las que, hasta que la aparición del investigador logra dar una explicación racional a lo sucedido, los sucesos criminales son explicados recurriendo a supersticiones folclóricas de carácter mítico y legendario: por citar algunos ejemplos sin ánimo de exhaustividad, en El hombre del revés (L'homme à l'envers, 1999) se alude a los hombres-lobo, en La tercera virgen (Dans les bois éternels, 2006) a los fantasmas, en Un lugar incierto 
(Un lieu incertain, 2008) a los vampiros, y en El ejército furioso (L'Armée furieuse, 2011) a los muertos vivientes.

\section{NOVELA NEGRA CON «SABOR LOCAL»}

De lo expuesto en las páginas precedentes puede deducirse cómo la serie narrativa protagonizada por Leo Caldas bascula entre su condición de producto de género - sometido, por tanto, a unas rígidas e identificables convenciones-y su singularidad. Las novelas de Villar son, de hecho, paradigmáticos ejemplos de literatura policiaca. No solo son presentadas como tales ante los lectores por su aparato paratextual, sino que además presentan elementos definitorios del género como el hecho de basar sus tramas argumentales en la investigación de un misterio criminal y asumen la tradición en la que se inscriben gracias a la constante inclusión de referentes literarios concretos. No obstante, poniendo de manifiesto que toda manifestación genérica se caracteriza por la dialéctica entre la unidad y la diferencia, Ojos de agua y La playa de los ahogados se distinguen por su valor costumbrista. Galicia no es simplemente el escenario en el que discurren las peripecias de Caldas, sino que se convierte en el elemento físico, social, humano y cultural capaz de dar a la serie narrativa creada por Domingo Villar un «sabor local» singular que la distingue del resto de propuestas de la literatura policiaca contemporánea.

\section{REFERENCIAS BIBLIOGRÁFICAS}

ALONSO, J. y SANTAMARÍA, P. (1991). Antología del relato policial. Barcelona: Vicens Vives.

AYALA DIP, J. (2009). «Misterios en el mar». El correo (http://info.elcorreo.com/territorios/articulo/lecturas/842531/misterios-en-el-mar.html).

BAENA, A. (2010). «Domingo Villar: Por fuera, mi obra es una novela policiaca, por dentro es un canto de amor a mi tierra». Atlántico Diario (http://www.atlantico.net/noticia.php?id=104496).

BALLÓ, J. y PÉREX, X. (2005). Yo ya he estado aquí. Ficciones de la repetición. Barcelona: Anagrama.

CASTRO, P. (2009). «La playa de los ahogados». El Cultural (http://www. elcultural.es/version_papel/LETRAS/26246/La_playa_de_los_ahogados).

COLMEIRO, J. F. (1994). La novela policiaca española. Teoría e historia crítica. Barcelona: Anthropos. 
DASILVA, X. M. (2009). «Autotraducirse en Galicia: ¿bilingüismo o diglosia?». Quadenrs. Revista de traducció 16, 143-156.

- (2013). Estudios sobre la autotraducción en el espacio ibérico. Berna: Peter Lang.

GARA CHEFIRI, I. (2010). «Escribir entre dos lenguas, el caso de Agustín Gómez Arcos». Logosphère: Je(ux) et language 6, 39-55.

MARTÍN ESCRIBÁ, A. y SÁNCHEZ ZAPATERO, J. (eds.) (2009). La lista negra. Nuevos culpables del policial español. Madrid: Salto de Página.

MADRID, J. (1986). «El viejo placer de leer intrigas». El País (24 de diciembre), 25.

MÍNGUEZ, M. (2010). «Domingo Villar: Es más fácil entender la historia de España leyendo a Vázquez Montalbán». El Mundo (http://www.elmundo.es/elmundo/2010/10/03/galicia/1286130050.html).

PEÑATE, J. (2010). Trayectorias de la novela policial en España. Francisco González Ledesma y Lorenzo Silva. Madrid: Visor Libros.

RESINA, J. R. (1997). El cadáver en la cocina. La novela criminal en la cultura del desencanto. Barcelona: Anthropos.

RIVERO GRANDOSO, J. (2011). «Crímenes y humor en las novelas de Domingo Villar». Madrygal. Revista de Estudios Gallegos 14, 109-116.

SÁNCHEZ DÍAZ, S. (2012). Un marco negro para un cuadro de costumbres. La narrativa policiaca de Domingo Villar [Trabajo de Fin de Máster Inédito]. Salamanca: Universidad de Salamanca.

SÁNCHEZ ZAPATERO, J. y MARTÍN ESCRIBÁ, A. (2010). «Teoría e historia de las sagas policiales en la literatura española contemporánea (1972-2007)». Dicenda 28, 289-305.

TANQUEIRO, H. (1999). «Un traductor privilegiado: el autotraductor». Quaderns. Revista de Traducció 3, 19-27.

TYRAS, G. (2003). Geografías de la memoria. Conversaciones con Manuel Vázquez Montalbán. Granada: Zoela.

VALLES CALATRAVA, J. R. (1991). La novela criminal española. Granada: Universidad de Granada.

VÁZQUEZ DE PARGA, S. (1993). La novela policiaca en España. Barcelona: Ronsel.

VENTURA, J. (2012). «Género negro en una ciudad patrimonio de la humanidad». En El género negro: el fin de la frontera, Javier Sánchez Zapatero y Àlex Martín Escribá (eds.), 135-148. A Coruña: Andavira. 
VILLAR, D. (2006). Ojos de agua. Madrid: Siruela.

- (2009). La playa de los ahogados. Madrid: Siruela.

- (2010). «Literatura de fermentación lenta». En Realidad y ficción criminal. Dimensiones narrativas del género negro, Javier Sánchez Zapatero y Àlex Martín Escribá (eds.), 63-70. Valladolid: Difácil.

Recibido el 3 de mayo de 2013.

Aceptado el 19 de septiembre de 2013. 